\title{
Points to Consider Regarding Tobacco Hindrance
}

\author{
Negar Rezaei, MD, PhD ${ }^{1}$; Farshad Farzadfar, MD, MPH, MHS, DSc ${ }^{1 *}$ \\ ${ }^{1}$ Non-Communicable Diseases Research Center, Endocrinology and Metabolism Population Sciences Institute, Tehran University of Medical \\ Sciences, Tehran, Iran
}

\section{Points to Consider Regarding Tobacco Hindrance} Tobacco use behavior has changed significantly over the past decades. Globally, 6\% and $5.43 \%$ of the total disability-adjusted life year (DALY) of all-cause is attributed to tobacco and cigarette smoking, respectively. In $2017,56.99 \%$ of larynx cancer, 53\% lung cancer, $35.8 \%$ of esophageal cancer, $34.94 \%$ of chronic obstructive pulmonary disease (COPD) , 32.63\% of bladder cancer, $26.97 \%$ of ischemic heart disease, $15.06 \%$ of diabetes, $14.4 \%$ of Alzheimer DALYs are attributed to tobacco consumption. ${ }^{1}$ The trend pattern of tobacco consumption has been decreasing globally from 1990 to $2017 .{ }^{1}$ Unfortunately, most of the current tobacco users live in low middle-income countries (LMIC). ${ }^{2}$ By decreasing the pattern of tobacco consumption in developed countries, tobacco industries shifted their market to LMIC. Low society awareness of tobacco risks and no potential advertisement bans are the main reasons for this shift. ${ }^{2}$ To confront this issue, Iran signed and ratified the WHO's Framework Convention on Tobacco Control (FCTC) by $2005 .{ }^{3}$ Since then, a comprehensive and systematic program for tobacco control legislation was established by the Iranian parliament based on the MPOWER strategy. The details of this strategy can be found elsewhere. ${ }^{4}$

In Iran, the overall age-standardized prevalence rates of ever tobacco use, ever daily cigarette smoking, current tobacco use, and current daily cigarette smoking are 21.1\% (95\% CI: 20.7 to 21.6), 14.6\% (95\% CI:14.2 to 15), $14.2 \%$ (95\% CI: 13.7 to 14.6 ), and $10.1 \%$ (95\% CI: 9.7 to 10.4 ), respectively. The male-to-female ratio of current daily cigarette smoking is about 22 . The prevalence is higher in rural areas compared to urban regions for all types of consumption. The prevalence of ever tobacco use and ever cigarette use in females is about $7 \%$ and $1.8 \%$, respectively. ${ }^{5}$ This reveals that the use of tobacco products other than cigarettes is 2.5 times more prevalent in Iranian women. The most popular form in young adults is water pipe smoke.

Based on the WHO prediction report in 2018, Iran could not achieve WHO goals and commitments on the tobacco control in $2025 .{ }^{6}$ Besides, Iran could not act properly on some aspects of the MPOWER strategy. First is direct and indirect advertisement on multimedia. Direct advertisements enforce tobacco industries to use unattractive colorless packing with life-threatening graphs and texts on it. There is only some graphical inhibition on Iranian market products that are not effective enough to halt or reduce tobacco consumption. There is no executive law in Iran to ban or reduce indirect smoking advertisements by celebrities through movies in cinema, TV or theaters or cyberspace, while the effectiveness of indirect advertisement ban policies on smoking initiation in minor or young adults has been demonstrated previously. ${ }^{4}$

Another issue is tax legislation on tobacco products. Raising tax on cigarette is a challenging argument between the Iranian Ministry of Health and Parliament. ${ }^{3}$ The main argument from the Parliament is low control on boundaries which result in the trafficking of tobacco products at a low price. ${ }^{7}$ Increasing tax on domestic products will result in bankruptcy of domestic tobacco industries and consequently, higher level of unemployment in the country. However, in 2018, the Parliament approved a $10 \%$ increase on cigarette price as a means for reducing cigarette use. This is a good sign but certainly not enough of a response from the Parliament's side.

The last issue is smoke-free available laws and enforcement. Based on the WHO report on global tobacco epidemic in 2019, a complete smoke-free law is not available or executed in restaurants and coffee shops, but they are available in other public places such as transportation, workplaces, and educational facilities except universities. ${ }^{4}$ Universities are not ultimate but have acceptable prohibiting laws. However, the compliance score on smoke-free air laws in Iran is 8 out of 10 , which is a good sign.

Despite all limitations, Iran ranked first in terms of the policy, legislation, and implementation of tobacco control laws in the East Mediterranean region, ${ }^{8}$ but it is still far from developed countries. In this regard, we need to urgently update and implement policies for decreasing tobacco consumption. 
To achieve this aim, we should have an overview of the most effective policies which have been used in other success stories. These policies include cigarette taxes, smoke-free air laws, comprehensive tobacco control programs, and marketing bans. These are reported to have an important role in reducing smoking prevalence. Cessation management policies and illustrated health warnings also reduce smoking in combination with quitting efforts strategies. ${ }^{8,9}$ There is scant large-scale evidence on the impact of health warnings due to tobacco industries' power and money and their impact on the market. ${ }^{2}$ Based on the WHO reports in $2019,{ }^{4}$ Iran needs to concentrate on price policies and taxing, marketing bans, and health warnings.

\section{Price Policies and Taxing}

Increasing the cigarette tax raises the purchase price. ${ }^{2} \mathrm{~A}$ $10 \%$ price increase will cause $1.8 \%$ and $1.9 \%$ decrease in prevalence and quantity of cigarette smoking, respectively. ${ }^{7}$ There are some points that need attention on this issue. First, the prevalence of quitting may highly fluctuate in young and low-income individuals. Second, the effectiveness of tobacco tax policies may not be feasible if the tax does not increase with income. It is well known that price effects depend on cigarette affordability. ${ }^{2,7,9}$ Tax and affordability of cigarettes are issues that have not been addressed properly in Iran. ${ }^{3,4}$ The Iranian Parliament needs to consider taxation as a critical issue for controlling national smoking.

\section{Marketing Bans}

Marketing restriction includes the prohibition on direct or indirect advertisements on mass media, billboards, TV productions, and cinemas, plus complete selling prohibition in the market. ${ }^{7}$ The former is only implemented in developed societies with high social awareness and low smoking prevalence. Complete ban strategy on selling cigarettes in the market is not feasible, although there are some small samples available in the literature. ${ }^{2}$ Hence, advertising prohibitions have been associated with a higher rate of cessation, mainly in highly educated groups and show long term effects on smoking commencements. A complete advertising ban reduces smoking prevalence by $4 \%$ and $6 \%$ in the short- and longterm, respectively. ${ }^{7}$ So, Iran needs to implement more practical and executable strategies and laws for increasing prohibition on indirect advertisement through mass media to reduce the prevalence of smoking and reverse the trend.

\section{Health Warnings}

Picture warnings show to have a $13 \%$ reduction in adult smoking prevalence. It also prevents nearly two-third of young adult from starting smoking in developed countries. However, the long-term effect of picture warnings is controversial, since individuals may get used to the appearance. There is limited evidence on the effect of plain packing. ${ }^{7}$ However, no laws are available on the obligation of plain packing in Iran. ${ }^{4}$

\section{Smoke-Free Air Laws}

Comprehensive smoke-free air laws that cover all indoor work places, restaurants and coffee shops are associated with $10 \%$ reduction in short-term relative risk of prevalence of smoking compared to no law. ${ }^{7}$ However, it is obvious that smoke-free policies have smaller effect in countries with low compliance due to fragile enforcement or absence of anti-tobacco social norms. ${ }^{10}$

Each policy may work completely differently in the context of variable societies with different socioeconomic status and education levels. Choosing a single policy is condemned to failure in most cases. Implementation of combined policies may raise the amount of success in all countries. ${ }^{7,9}$ Compared to developed countries, Iran has a huge gap in ratification and execution laws in the advertisement, smoke-free laws in restaurants and coffee shops, and tax strategies. ${ }^{4}$ It is recommended to consider this issue as a priority in the serious national fight against tobacco abuse.

\section{Authors' Contributions}

$\mathrm{NR}$, writing article; FF, writing article.

\section{Conflict of Interest Disclosures}

None.

\section{Ethical Statement}

Not applicable.

\section{References}

1. IHME. GBD Compare: IHME Viz Hub - Data Visualizations. Available from: https://vizhub.healthdata.org. Accessed October 6, 2019.

2. Smith EA, Malone RE. An argument for phasing out sales of cigarettes. Tob Control. 2019 Sep 21. doi: 10.1136/ tobaccocontrol-2019-055079.

3. Alimohammadi $M$, Jafari-Mansoorian $H$, Hashemi SY, Momenabadi V, Ghasemi SM, Karimyan K. Review on the Implementation of the Islamic Republic of Iran about Tobacco Control, Based on MPOWER, in the Framework Convention on Tobacco Control by the World Health Organization. Addict Health. 2017;9(3):183-189.

4. World Health Organization. WHO global report on trends in prevalence of tobacco smoking 2000-2025 . Available from: https://www.who.int/tobacco/surveillance/policy/country_ profile/irn.pdf. Accessed October 6, 2019.

5. Non Communicable Disease Research Center TUoMS. Data visualization system. Available from: https://vizit.report/panel/ steps. Accessed October 6, 2019.

6. World Health Organization. Noncommunicable diseases country profiles, 2018. Available from: https://www.who.int/ nmh/publications/ncd-profiles-2018/en/. Accessed October 6, 2019.

7. Levy DT, Tam J, Kuo C, Fong GT, Chaloupka F. The Impact of Implementing Tobacco Control Policies: The 2017 Tobacco Control Policy Scorecard. J Public Health Manag Pract. 2018;24(5):448-457. doi: 10.1097/PHH.0000000000000780. 
8. Banks C, Rawaf S, Hassounah S. Factors influencing the tobacco control policy process in Egypt and Iran: a scoping review. Glob Health Res Policy. 2017;2:19. doi: 10.1186/ s41256-017-0039-6.

9. Paoletti L, Jardin B, Carpenter M, Cummings KM, Silvestri GA. Current status of tobacco policy and control. J Thorac Imaging.
2012;27(4):213-9. doi:10.1097/RTI.0b013e3182518673.

10. Nesoff ED, Milam AJ, Bone LR, Stillman FA, Smart MJ, Hoke $\mathrm{KS}$, et al. Tobacco policies and on-premise smoking in bars and clubs that cater to young African Americans following the Maryland Clean Indoor Air Act of 2007. J Ethn Subst Abuse. 2017;16(3):328-343. doi: 10.1080/15332640.2016.1196631.

Received: October 13, 2019, Accepted: January 26, 2020, ePublished: May 1, 2020

Cite this article as: Rezaei N, Farzadfar F. Points to consider regarding tobacco hindrance. Arch Iran Med. 2020;23(5):353-355. doi: 10.34172/aim.2020.25. (c) (1) (c) 2020 The Author(s). This is an open-access article distributed under the terms of the Creative Commons Attribution License (http://creativecommons. org/licenses/by/4.0), which permits unrestricted use, distribution, and reproduction in any medium, provided the original work is properly cited. 